\title{
BMJ Open Changes in work stress among doctors in Norway from 2010 to 2019: a study based on repeated surveys
}

\author{
Judith Rosta (D) , ${ }^{1}$ Fredrik Bååthe, ${ }^{1,2}$ Olaf G Aasland, ${ }^{1}$ Karin Isaksson Rø ${ }^{1}$
}

To cite: Rosta J, Bååthe $F$, Aasland OG, et al. Changes in work stress among doctors in Norway from 2010 to 2019: a study based on repeated surveys. BMJ Open 2020;10:e037474. doi:10.1136/ bmjopen-2020-037474

- Prepublication history for this paper is available online. To view these files, please visit the journal online (http://dx.doi. org/10.1136/bmjopen-2020037474).

Received 04 February 2020 Revised 21 August 2020 Accepted 26 August 2020

Check for updates

(C) Author(s) (or their employer(s)) 2020. Re-use permitted under CC BY-NC. No commercial re-use. See rights and permissions. Published by BMJ.

${ }^{1}$ Institute for Studies of the Medical Profession, 0slo, Norway

${ }^{2}$ Institute of Stress Medicine, Gothenburg, Sweden

Correspondence to Dr Judith Rosta; judith.rosta@legeforeningen.no

\section{ABSTRACT}

Objectives To explore and discuss the changes in the levels of work stress for Norwegian doctors in different job positions (hospital doctors, general practitioners (GPs), private practice specialists, doctors in academia) from 2010 to 2019.

Design Repeated questionnaire surveys in 2010, 2016 and 2019, where samples were partly overlapping.

Setting Norway.

Participants A representative sample of 1500-2200 doctors in different job positions. Response rates were $66.7 \%(1014 / 1520)$ in 2010, 73.1\% (1604/2195) in 2016 and $72.5 \%(1511 / 2084)$ in 2019.

Main outcome measure Validated 9-item short form of the 'Effort-Reward Imbalance' questionnaire. A risky level of work stress was defined as an effort/reward ratio above 1.0 .

Analyses Linear mixed models with estimated marginal means of job positions controlled for gender and age. Proportions with $95 \%$ Cls.

Results From 2010 to 2016 and further to 2019, GPs reported a significant increase in levels on the effort scale (ES: 2.96, 3.25, 3.51) and significant decrease in levels on the reward scale (RS: 4.27, 4.05, 3.67). No significant changes were reported by hospital doctors (ES: 3.13, 3.10, 3.14; RS: $4.09,3.98,4.04$ ), private practice specialists (ES: 2.58, 2.61, 2.59; RS: 4.32, 4.32, 4.30) and doctors in academia (ES: 2.63, 2.51, 2.52; RS: 4.09, 4.11, 4.14). The proportion of doctors with risky levels of work stress increased significantly for GPs $(10.3 \%, 27.7 \%, 40.1 \%)$, but did not significantly change for hospital doctors $(23.0 \%$, $27.3 \%, 26.9 \%)$, private practice specialists $(8.2 \%, 12.7 \%$, $9.4 \%)$ and doctors in academia (11.9\%, 19.0\%, 16.4\%). Conclusion During a 9-year period, the proportion of risky levels of work stress increased significantly for GPs but did not significantly change for other job positions. This may be partly due to changes in expectations of younger GPS and several healthcare reforms and regulations.

\section{BACKGROUND}

Doctor burn-out is prevalent internationally, and has been found to have negative consequences for individual doctors, quality of patient care and healthcare organisations. ${ }^{12}$ Burn-out is a response to prolonged exposure to occupational stressors. ${ }^{3}$ Regular assessments of work-related stress, followed by analyses and appropriate actions, are therefore

\section{Strengths and limitations of this study}

The unbalanced cohort design on doctors' work stress, with high response rates and near representativity of practising doctors in Norway, provided a solid basis for generalisation of the results.

- The Effort-Reward Imbalance questionnaire was not specifically designed for doctors but has been validated and used extensively in doctor populations, both in Norway and elsewhere.

- Analyses were based on self-reported questionnaire data with the possibility of both overerestimation and underestimation of the various components of working conditions in the Effort-Reward Imbalance questionnaire.

important to prevent and reduce burnout rates. This will have an important impact both on the individual and on the systemic level.

A widely used model to measure workrelated stress is the Effort-Reward Imbalance (ERI) model proposed by Siegrist. ${ }^{4}$ According to this model, an imbalance between high efforts spent at work and low rewards received, in turn, lead to emotional distress and increases the risk of poor health, including burnout and sick days. ${ }^{5-10}$ The effort scale refers to demanding aspects of the work environment such as time pressure, interruptions/disturbances, high responsibility and increasing demands. The reward scale includes income and aspects of career development by measuring promotion prospects, undesirable change, job stability and security, respect and prestige, and adequate income. In addition to assessing the general imbalance between efforts and rewards, analysing changes in separate effort and reward items can indicate specific work aspects to focus on when aiming to reduce stress.

Aspects both of efforts and rewards, like number of work hours, workload (eg, time pressure) and job satisfaction have been closely monitored among Norwegian doctors since $1993 .{ }^{11-13}$ During the last years, there 
have been worrying changes in these measures. Surveys from 2018 report long working weeks with an increasing variety of tasks, together with a growth in work demands for general practitioners (GPs). ${ }^{14}{ }^{15}$ This is consistent with similar reports from other countries. ${ }^{16-18}$ Studies also show an increased workload and threatened professional autonomy for hospital doctors. ${ }^{19}$ Another recent study shows a significant decrease in several aspects of job satisfaction (such as the freedom to choose methods of work, recognition for good work, rate of pay and work hours) both for GPs and hospital doctors from 2010 to 2017, suggesting changes in working conditions could be a central reason for this. ${ }^{11}$ In a qualitative interview-based study, Norwegian hospital doctors described increasing workplace emphasis on production numbers and budget concerns. In addition to experiencing the need to stretch themselves far to handle the tension between quantity and quality, the doctors felt less aligned with workplace values and experienced limited management recognition for assuring good quality of patient care. ${ }^{20}$ However, total weekly working hours remained unchanged for most Norwegian doctors during this period. ${ }^{13}$ GPs, doctors in hospital management positions and doctors in academia have reported longer working weeks than doctors in other job positions in almost all the surveys. ${ }^{13}$ International studies have shown varying results regarding in which job positions doctors experience the most stress. GPs have been found to experience more stress than hospital doctors, ${ }^{21}$ whereas private practitioners reported less stress than doctors in the public sector. ${ }^{22}$ In other studies, no differences were found between different job positions. $^{5} 1223$

Recent studies have, as described above, indicated changes in both job demands and resources, and accompanying reductions in satisfaction for doctors in different job positions have been found. Is this associated with changes in levels of work stress? This study explores experienced work stress among Norwegian doctors, measured as ERI and analysed in relation to different job positions (hospital doctors, GPs, private practice specialist, doctors in academia) from 2010 to 2019.

\section{MATERIAL AND METHODS}

\section{Participants and ethical approval}

Since 1994, The Institute for Studies of the Medical Profession in Norway has, every second year, surveyed a representative sample of 1500-2200 active doctors with postal questionnaires about their health, quality of life and working conditions. The sample represents an unbalanced cohort in that respondents who leave the panel due to retirement, death or voluntary withdrawal are replaced by younger doctors, while the sample's representative nature is maintained at all times. ${ }^{13}$ This article is based on data from 2010, 2016 and 2019 (the latter partly collected at the end of 2018).

Informed consent was obtained from all participants in the surveys, as well as an exemption from a specific review of the individual surveys from the Regional Committee for Medical Research Ethics.

\section{Measurements}

Main outcome measurements

Work stress

The level of work stress was measured by the validated nine-item short form of the ERI questionnaire. This shortform questionnaire comprises 4 out of 6 items from the effort scale and 5 out of 11 items from the reward scale of the original ERI questionnaire. ${ }^{24}$ This short version was tested previously in different samples and proved to correlate well with the original measure, with Cronbach's alpha varying from 0.86 to $0.63 .{ }^{25}$ Descriptions of the score changes on the separate items help to explain which changes on the effort scale and reward scale were the most important over time. ${ }^{1225}$

Estimations were given on five-point Likert scales. On the effort scale: (1) disagree; (2) agree and I am not at all distressed; (3) agree and I am somewhat distressed; (4) agree and I am distressed; (5) agree and I am very distressed. On the reward scale: (1) agree; (2) disagree and I am not at all distressed; (3) disagree and I am somewhat distressed; (4) disagree and I am distressed; (5) disagree and I am very distressed. After appropriate recoding of response alternatives on the reward scale, high scores indicate high perceived effort and high perceived reward at work. ${ }^{124}$

\section{Effort scale}

1. I have constant time pressure due to a heavy workload.

2. I have a lot of responsibility in my job.

3. I have many interruptions and disturbances in my job.

4. Over the past few years, my job has become more and more demanding.

\section{Reward scale}

5 . The prospects of my further job development are poor.

6 . I have experienced, or I expect to experience, an undesirable change in my work situation.

7. My job security is poor.

8. Considering all my efforts and achievements, I receive the respect and prestige I deserve for my work.

9. Considering all my efforts and achievements, my income is adequate.

\section{Risky levels of work stress}

According to the ERI model, risky levels of work stress are rooted in a chronic mismatch between high effort and low reward. Hence, a ratio of the sum score of the effort items (nominator) relative to sum score of the reward items (adjusted for the number of items; denominator) greater than one indicates risky levels of work stress. ${ }^{12} 24$

\section{Effect variables}

Main job positions were categorised into the following groups:

1. Hospital doctors: specialty registrars, senior hospital consultants and doctors in hospital management 
positions (medical superintendent, head of department, chief senior consultant, head of the unit, senior consultant, head of section).

2. General practitioners (GPs).

3. Specialists working in private practice.

4. Doctors in academia (professor, associate professor, research fellow, researcher).

5. Doctors in administrative positions (county medical officer, medical adviser, chief medical officer).

6. Community medical officers (district medical officer, senior district medical officer, nursing home medical officer, visiting medical officer, doctor at infant welfare clinic).

7. Other job positions.

Other variables were gender and age.

\section{Inclusion and exclusion criteria}

Doctors with data on gender, age ( $<70$ years), job positions and all nine items of the ERI questionnaire were included in the study. Because internship was not specifically identified as a defined group in the data before 2016, we excluded this category in the present paper.

\section{Analyses}

All job positions (hospital doctors, GPs, private practice specialist, doctors in academia, doctors in administrative position, community medical officers, other job positions) were included in the analyses. To describe the changes in the levels of the effort scale and the reward scale, as well as the level of each item on both scales over time, multivariable linear mixed models with a subject-specific random intercept were used. The estimates of means and 95\% CIs and tests of comparisons are based on statistical models for repeated measurements. The scale of interest is the dependent variable and the job position, age $(<50$ years of age and $\geq 50$ years of age) and gender are independent variables in the models. The proportion of risky levels of work stress (ie, ratio scores of the sum score of the effort items relative to the sum score of the reward items $>1$ ) were also calculated. The effect size given as the OR for repeated measures of the proportion of risky levels of work stress was calculated within each job position using the generalised estimating equation with an unstructured covariance matrix. Descriptions of results in detail (including in tables and figures) were undertaken among hospital doctors, GPs, specialists in private practice and doctors in academia. For doctors in other job positions (doctors in administrative position, community medical officers, other job positions), changes in the levels of the effort scale and reward scale as well as the proportion of risky levels of work stress were presented in the text. Units with missing data were excluded. The data were analysed using the IBM SPSS statistics software, V.26.

\section{Patient and public involvement}

This study is important for patients because healthy doctors take better care of their patients. However, in this survey, we have no access to direct patient involvement.
No patients were involved in setting the research question or the outcome measures, nor were they involved in the design and implementation of the study. We strive to publish the results also in a more popular format to reach potential patients in society, outside the scientific community.

\section{RESULTS}

\section{Respondents}

Table 1 presents the sample, respondents, response rates and the range of job positions for doctors for which we had data on gender, age and all items of the ERI model in 2010, 2016 and 2019. It also describes how the respondents compares with all active doctors in Norway. The amount of missing data was $n=93$ in 2010, n=210 in 2016 and $n=219$ in 2019. The response rates varied from $67 \%$ in 2010 to $73 \%$ in 2016 and 2019. The distribution of the doctors in different job positions was comparable over the study period. The only exception was interns. Because of the low number of interns in $2010(\mathrm{n}=0)$ and 2019 $(\mathrm{n}=17)$, this group was excluded in the analyses.

The demographic characteristics between the 3 years groups were slightly different: The sample in 2010 had a lower proportion of females $(37.6 \%, 95 \%$ CI 32.5 to $42.7)$ and higher age in years (49.5, SD 10.4) than the samples in 2016 and 2019. In the sample from 2016 and 2019 , mean age in years $(43.3$, SD 13.0 vs 44.6 , SD 12.2) and proportion of females $(52.0 \%, 95 \%$ CI 49.4 to 54.6 vs $52.9 \%, 95 \%$ CI 50.2 to 55.6 ) were similar.

In terms of age, gender and job positions, the distributions of our samples in 2010 and 2016 were similar to the distributions found in the Statistics on all Members of the Norwegian Association, which includes 97\% of all active doctors in Norway. ${ }^{11}$ In 2019, the distribution of our sample was representative of that of these statistics with respect to age and gender, and varied slightly regarding some job positions (hospital doctors, doctors in academia, interns, other positions).$^{26}$

\section{Changes in estimated marginal means on the effort scale and reward scale \\ Within job positions}

From 2010 to 2016 and further to 2019, GPs reported a significant increase in levels on the effort scale and a significant decrease in levels on the reward scale. For hospital doctors, there was no significant change related to the effort scale, but there was a temporary significant decrease on the reward scale from 2010 to 2016, with a subsequent increase again in 2019. No significant changes were reported by private practice specialists and doctors in academia (figure 1 ).

We found no significant changes in the levels on the effort scale and on the reward scale for doctors in other positions like doctors in administrative positions (effort scale: $2.78,2.46,2.45$; reward scale: $4.04,4.25,4.18$ ), and community medical officers (effort scale: 2.76, 2.61, 
Table 1 Sample, respondents, response rates and the range of job positions for doctors with data on gender, age and all items of the ERI model in 2010, 2016 and 2018-2019, and comparison of respondents in 2018-2019 with all active doctors aged $<70$ years in Norway in 2018

\begin{tabular}{|c|c|c|c|c|}
\hline & \multicolumn{3}{|c|}{ Respondents aged $<70$ years in Norway } & \multirow{2}{*}{$\begin{array}{l}\text { All active doctors } \\
\text { aged }<70 \text { years in } \\
\text { Norway } \\
2018 \\
\end{array}$} \\
\hline & 2010 & 2016 & 2018-2019* & \\
\hline Sample, $n$ & 1520 & 2195 & 2084 & - \\
\hline Respondents, $\mathrm{n}$ & 1014 & 1604 & 1511 & - \\
\hline Response rate, \% & 66.7 & 73.1 & 72.5 & - \\
\hline All,$\uparrow n$ & 921 & 1394 & 1292 & 27540 \\
\hline \multicolumn{5}{|l|}{ Gender, n (\%) } \\
\hline Male & $575(62.4)$ & $669(48.0)$ & $609(47.1)$ & $13715(49.8)$ \\
\hline Female & $346(37.6)$ & $725(52.0)$ & $683(52.9)$ & 13825 (50.2) \\
\hline \multicolumn{5}{|l|}{ Mean age, mean (SD) } \\
\hline All & $49.5(10.4)$ & $43.3(13.0)$ & $44.6(12.2)$ & 44.5 \\
\hline \multicolumn{5}{|l|}{ Job positions, n (\%) } \\
\hline Hospital doctors & $517(56.1)$ & $755(54.2)$ & $797(61.7)$ & $13706(49.8)$ \\
\hline General practitioners & 214 (23.2) & 249 (17.9) & $232(18.0)$ & $4735(17.2)$ \\
\hline Specialists in private practice & $61(6.6)$ & $55(3.9)$ & $53(4.1)$ & $877(3.2)$ \\
\hline Doctors in academia & $59(6.4)$ & $58(4.2)$ & $67(5.2)$ & $716(2.6)$ \\
\hline Community medical officers & $25(2.8)$ & $54(3.9)$ & $55(4.3)$ & $1026(3.7)$ \\
\hline Doctors in administrative position & $18(2.0)$ & $30(2.2)$ & $23(1.8)$ & $432(1.6)$ \\
\hline Interns & - & $143(10.2)$ & $17(1.3)$ & $997(3.6)$ \\
\hline Other positions & $27(2.9)$ & $50(3.5)$ & $48(3.6)$ & $5050(18.3)$ \\
\hline
\end{tabular}

*Data from 2019 (the latter partly collected at the end of 2018).

†Respondents with no data on ERI, or gender or age ( $\geq 70$ years) were 93 in 2010, 210 in 2016 and 219 in 2019.

ERI, Effort-Reward Imbalance.

2.83; reward scale: 4.31, 4.12, 4.12) (data not shown in figure 1).

\section{Comparisons across job positions}

Figure 1 illustrates the changes in the scores of effort scale and reward scale based on multivariate linear mixed models. On the effort scale, GPs had significantly lower scores than hospital doctors and significantly higher scores than doctors in academia and private practice specialists in 2010. The scores in 2016 and 2019 were significantly higher for GPs than for doctors from the other three job positions.

On the reward scale, GPs reported significantly higher scores than hospital doctors in 2010 and significantly lower scores than private practice specialists in 2016. In 2019, the scores for GPs were significantly lower than for doctors in the other three job positions (figure 1).

Doctors in administrative positions and community medical officers compared with GPs reported similar levels of effort scale and reward scale in 2010, while the level of effort scale was significantly lower and the reward scale significantly higher in 2019 (data not shown).
Changes in estimated marginal means on the item level

Table 2 describes the changes in the levels of each item on the effort scale and the reward scale over time based on the multivariable linear mixed models.

\section{Within job position}

Between 2010 and 2019, the scores on the effort items (ERI 1: time pressure, ERI 2: responsibility, ERI 4: demands) with the exception of the third item (ERI 3: many interruptions) increased significantly and the scores on the reward items (ERI 5: promotion prospects, ERI 6: undesirable change in the work situation, ERI 7: job security, ERI 8: respect and prestige, ERI 9: adequate income) decreased significantly for GPs. For doctors in other positions, the scores of items did not change significantly (table 2).

\section{Comparisons across job positions}

Statistically significant differences in estimated marginal means across job positions with GPs as reference were calculated within each year. For all the items (except for ERI 3: I have many interruptions and disturbances in my job) GPs scored significantly more unfavourably in 2019 


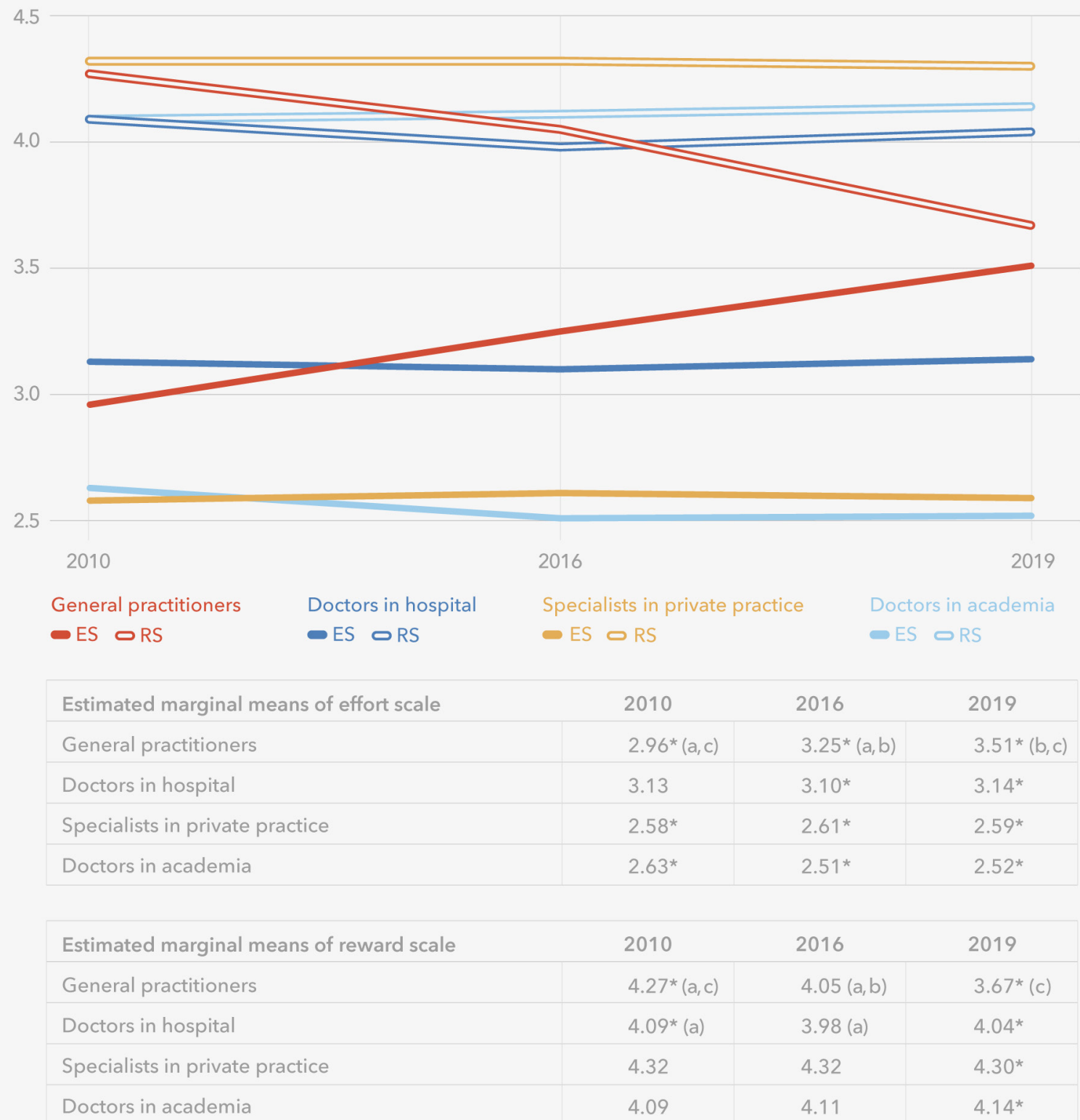

Figure 1 Multivariable linear mixed models with estimated marginal means of effort scale (ES) and reward scale (RS) with fixed factors of job positions, gender and age in 2010, 2016 and 2019. High values indicate high effort/reward, ranged from 1 to 5. (a) Statistically significant changes in estimated marginal means from 2010 to 2016 within job position. (b) Statistically significant changes in estimated marginal means from 2016 to 2019 within job position. (c) Statistically significant changes in estimated marginal means from 2010 to 2019 within job position. *Statistically significant differences in estimated marginal means across job positions with general practitioners as reference, within each year.

than in 2010, and the levels of several items were more unfavourable than for the other job positions in the three time points (table 2).

\section{Risky levels of work stress}

Within job positions

From 2010 to 2016 and further to 2019, the proportion of risky levels of work stress increased significantly for GPs, while no significant changes were found for doctors from the other three job positions (figure 2).

We did not find significant changes for doctors in administrative positions $(5.6 \%, 95 \%$ CI 1 to $16.2 ; 10.0 \%$,
1 to $20.7 ; 8.7 \%, 1$ to 22.1 ) or for community medical officers $(12 \%, 1$ to $24.7 ; 13.0 \%, 4.0$ to $22.0 ; 23.6 \%, 12.4$ to 34.8) (data not shown in figure 2).

\section{Comparison across job positions}

The proportion of risky levels of work stress for GPs was significantly lower than for hospital doctors in 2010 and significantly higher than for doctors from the other three positions in 2019 (figure 2). The effect size given as OR for repeated measures of the risky levels of work stress were significant for GPs from 2010 to 2016 (OR 3.2, 95\% CI 2.1 to 5.0, $\mathrm{p}=0.0001$ ) and 2010 to 2019 (OR 5.7, 


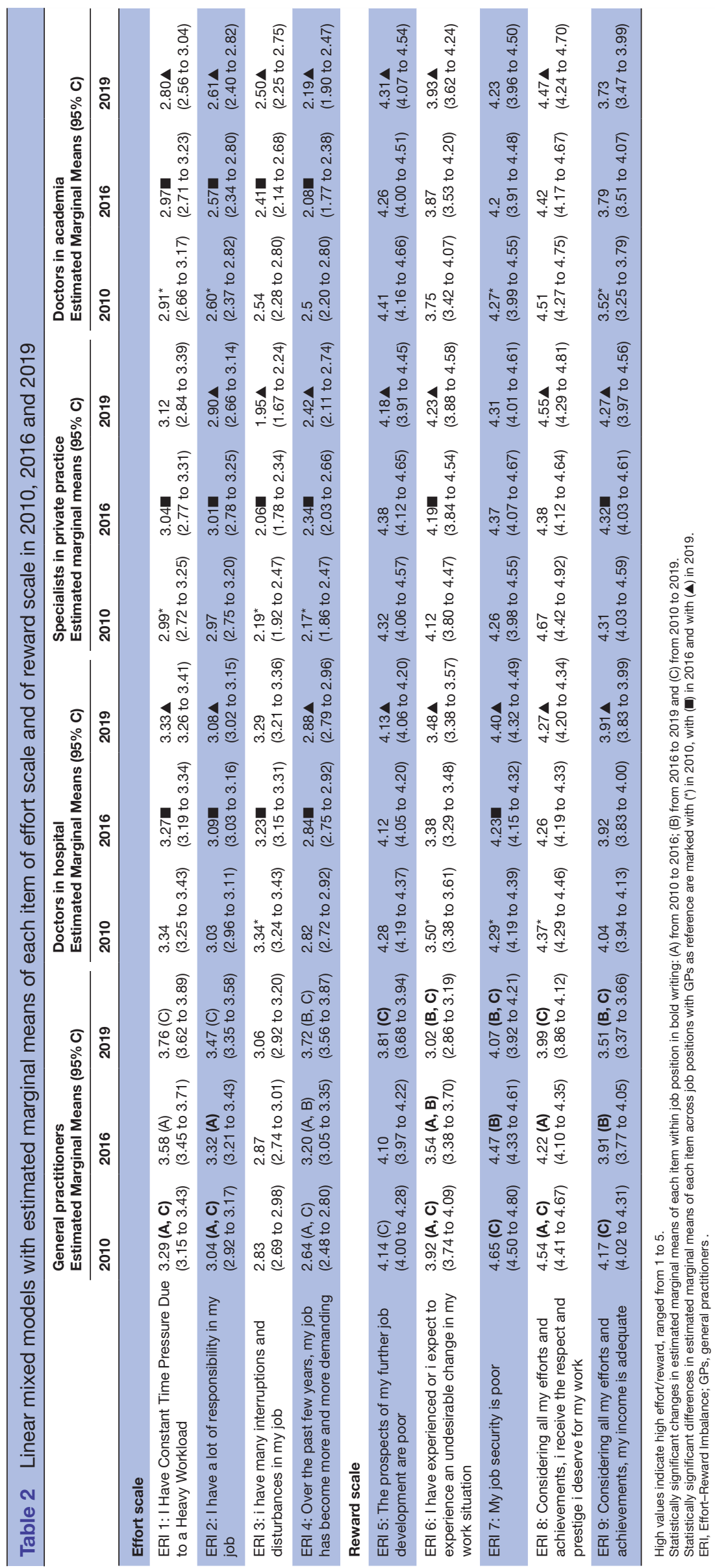




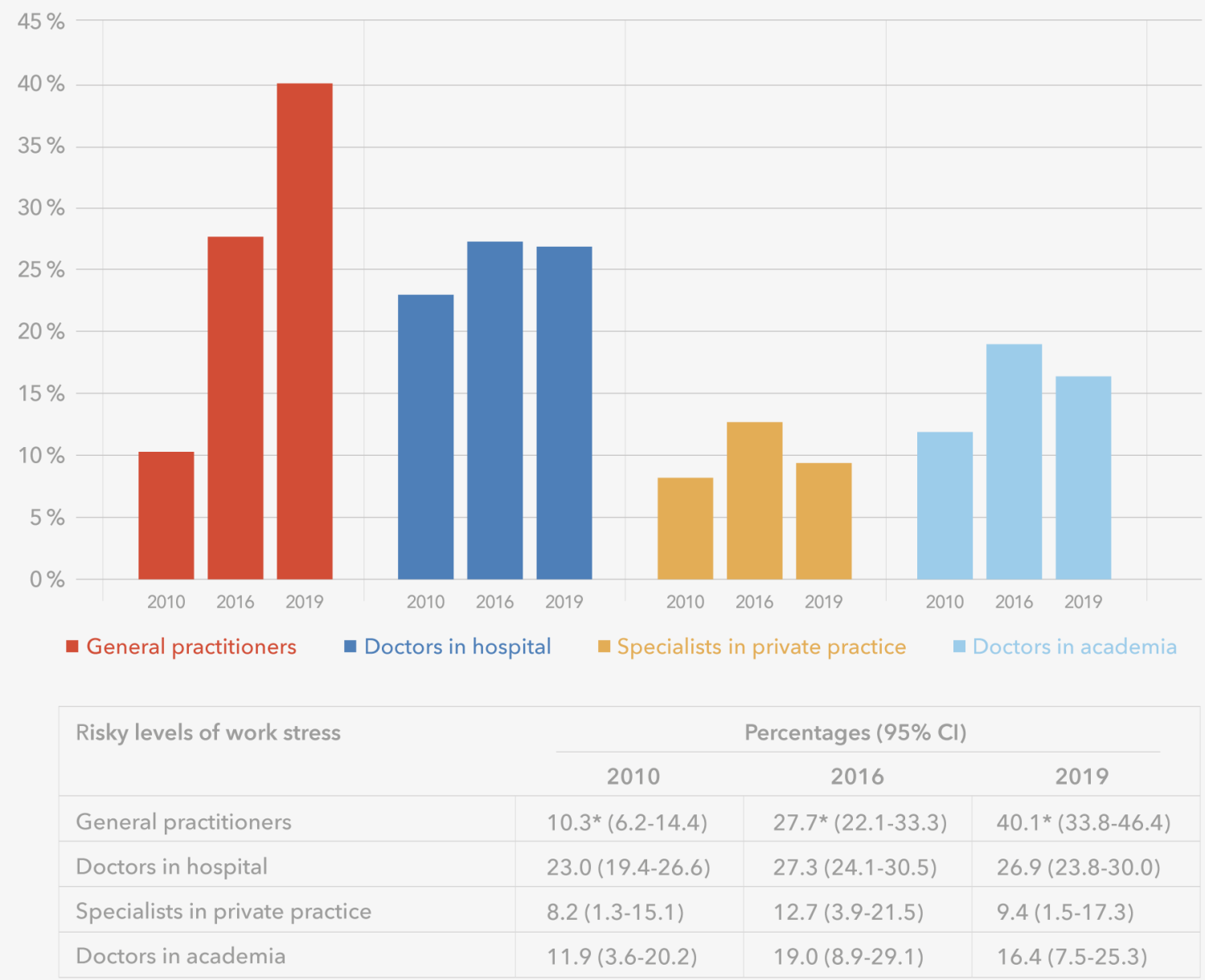

Figure 2 Proportions of risky levels of work stress for doctors in different job positions in 2010, 2016 and 2019. *Statistically significant changes in proportions of risky levels of work stress.

$95 \%$ CI 3.7 to $8.8, \mathrm{p}=0.0001$ ), while no significant results were found for doctors from other job positions.

GPs compared with community medical officers (27.7\%, 95\% CI 22.1 to 33.3 vs $13.0 \%, 4.0$ to 21.9$)$ reported a significantly higher proportion of risky levels of work stress in 2016, and compared with doctors in administrative positions significantly higher proportions of risky levels of work stress in $2016(27.7 \%, 22.1$ to $33.3 \mathrm{vs}$ $10.0 \%, 1$ to 20.7$)$ and $2019(40.1 \%, 33.8$ to 46.4 vs $8.7 \%$, 1 to 20.2) (data not shown in figure 2).

\section{Positive imbalance (more rewards and fewer efforts) or no imbalance}

The majority of doctors experienced positive imbalance (more rewards and fewer efforts) or no imbalance in 2010, 2016 and 2019. The proportion of positive imbalance or no imbalance was highest among specialists in private practice $(91.8 \%, 95 \%$ CI 84.6 to $98.9 ; 87.3 \%$, 77.9 to $96.7 ; 90.6 \%, 82.3$ to 98.9 ), followed by doctors in academia $(88.1 \%, 79.3$ to $96.9 ; 81.0 \%, 69.8$ to 92.2 ; $83.6 \%, 73.9$ to 93.3$)$ and hospital doctors $(77.0 \%, 72.7$ to $81.1 ; 72.7 \%, 69.0$ to $76.4 ; 73.1 \%, 69.5$ to 76.7$)$. GPs reported a decrease in the proportion of positive imbalance or no imbalance $(89.7 \%, 85.4$ to $93.9 ; 72.3 \%, 65.7$ to $78.8 ; 59.9 \%, 51.8$ to 68.0 ), while doctors from other job positions reported no changes.

\section{DISCUSSION}

\section{Main findings}

From 2010 to 2016 and further to 2019, three of the four scores on the effort items (time pressure, responsibility, demands) increased significantly and the scores on the reward items (promotion prospects, undesirable change in the work situation, job security, respect and prestige, adequate income) decreased significantly for GPs but were not significantly changed for doctors in other positions. The proportion of risky levels of work stress (ie, imbalance between high efforts spent at work and low rewards at work received in turn) increased significantly for GPs $(10.3 \%, 27.7 \%, 40.1 \%)$ while it stayed at a relatively high level for hospital doctors $(23.0 \%, 27.3 \%$, $26.9 \%)$. 


\section{Comparison with other studies}

Differences in methodology regarding data collection, sample composition and measurements limit direct comparisons with other studies. The ERI criterion of risky levels of work stress (Effort-Reward ratio >1.0), however, seems to be less prevalent in our Norwegian sample (figure 2) compared with $28 \%$ private practice specialists and GPs in Germany in 2010, ${ }^{12} 64.9 \%$ of hospital doctors in Switzerland in $2015-2016^{27}$ and $57 \%$ of doctors in Germany in $2014 .^{28}$

Perceived work stress among doctors across job positions shows a mixed picture. In a UK study, a higher percentage of GPs than hospital doctors perceived their job as 'often or always stressful' (69\% vs $51 \%) .{ }^{21}$ In Germany, work stress as measured by ERI was similar among hospital doctors in surgical fields (females: 24\%, males 26\%) and private practice specialists (including GPs) $(28 \%) .{ }^{512} \mathrm{~A}$ Finnish study found only a small difference between GPs and consultants in psychological stress using the 12-item version of the General Health Questionnaire, ${ }^{23}$ while another Finnish study describes the working environment for doctors in the public sector as more strenuous than for doctors in the private sector. ${ }^{22}$ In our sample, GPs and private practice specialists had similar proportions of risky levels of work stress in 2010, while the levels were significantly higher for GPs in 2016 and 2019. GPs compared with other job positions had significantly the highest proportion of risky levels of work stress in 2019 (figure 2).

In the Norwegian 'Working environment and living condition survey', there was a slight decrease in the ERI (effort in the work and the reward they receive in the form of recognition or payment based on two items) among the general population from $13 \%$ in 2009 to $11 \%$ in 2013 and 2016. In data from 2016, social workers $(20 \%)$, nurses $(19 \%)$ and policemen $(19 \%)$ reported higher proportions and carpenters $(7 \%)$, engineers $(8 \%)$ and construction workers $(10 \%)$ lower proportions than doctors $(11 \%) .^{29}$ Differences in the prevalence of ERI among doctors in this population-based study compared with our study (figure 2) may be due to different measurement instruments (two items vs nine items) and different composition of doctors (all doctors vs doctors in different job positions).

\section{Reflection about variations in the work stress across job positions}

Healthcare systems are constantly subject to change in most Western countries, including Norway. Doctors are confronted with numerous regulations and administrative duties that limit their professional autonomy and financial security. These conditions have previously been shown to add to the doctors' levels of work-related stress. $^{25} 3031$

Two major healthcare reforms have been implemented over the last decade in Norway: 'The Co-ordination Reform' in 2012 aims at better collaboration between primary (municipal) and secondary (specialist) healthcare levels and more prevention, and 'The Future Primary Care-Proximity and Comprehensiveness' in 2015 was implemented to improve patient involvement, prevention, proactivity and better collaboration between multidisciplinary teams. These reforms may explain some of the increase in work stress, especially for GPs in Norway. The reforms have been criticised because they lead to a considerable increase in both work demand and the cost of running their own medical office for GPs during the last decade. The high work demand was related to increased transfer of tasks that were previously conducted by outpatient clinics or hospitals, for example, follow-up care of pregnant women or patients with chronic diseases like cancer, rheumatic diseases, endocrinological disease, substance abuse and some mental health disorders. ${ }^{32}$ In addition, there was an increase in consultations, laboratory services for appointment specialists, tasks related to preventive treatment and documentation as well as certification requirements. ${ }^{33}$ A study among GPs in 2018 showed the potential negative effects of task shifting from hospital specialists and other specialists to GPs on patient safety such as the hazardous delay of necessary examinations, or insufficient treatment due to lack of resources or risk of malpractice. ${ }^{34}$ A study with data from 2018 documented long working weeks with a wide variety of tasks among GPs. ${ }^{1415}$ The evaluation study of 'The Regular General Practitioners Scheme' from $2019^{35}$ confirmed significant growth in workloads for GPs during the last years that were related to increase both in new tasks and in the volume of established tasks. In this study, every tenth GP reported to the municipality that they want to quit general practice, mainly because of high workloads. The prevalence of GPs among all practising doctors in Norway was $17 \%$ in $2018,{ }^{26}$ however, there were only $9 \%$ of interns and medical students who wished to work as a GP. ${ }^{35}$ Barriers to choosing general practice among interns and medical students were high workload, lack of financial security and absence of social regulations that safeguarded them or their families in case of illness. ${ }^{35}$

These findings fit well with our data from 2010 to 2016 and further to 2019, where for GPs three of four items of the effort scale increased significantly (time pressure, responsibility, increased demand) and all five items of the reward scale decreased significantly (income, respect and prestige, undesirable change in the work situation, job stability, promotion prospects). This yielded a significant increase in the imbalance between high effort and low reward, ie, risky levels of work stress increased from $10.3 \%$ to $27.7 \%$ and further to $40.1 \%$. The large effect size for changes from 2010 to 2019 (OR 5.7) and for 2010 to 2016 (OR 3.2) underline the importance of the changes in the proportion of risky levels of work stress for GPs. A study with Norwegian data from 2010 to 2017 showed that for GPs and hospital doctors, satisfaction decreased significantly with several aspects of job conditions like 'freedom to choose methods', 'recognition for good work', 'rate of pay' and 'work hours'. In addition, GPs reported significantly lower scores for 'amount of responsibility' and 
'overall job satisfaction', suggesting changes in working conditions. ${ }^{11}$ Increasing workload for GPs seems to be common for Western countries. Studies from Denmark, ${ }^{16}$ Australia ${ }^{17}$ and the $\mathrm{UK}^{18}$ document increased workload and declining job satisfaction over the last 10 years.

Long working hours is one of the important contributors to work stress. ${ }^{36}$ A study based on data from 1994 to 2014 showed that the total weekly working hours remained unchanged for most doctors in Norway, while time spent on direct patient care decreased, suggesting an increasing need to spend time on tasks like documenting, reporting and encoding in the health sector. ${ }^{13}$ Taken together, this indicates that it is not enough to measure the number of hours worked (the quantity), it is also important to study the content of the work (the quality). In a survey of hospital doctors' working conditions in 2018, hospital doctors scored high on items related to engagement at work, assessment of work as meaningful and cooperation with colleagues, but lower on items related to workload and professional autonomy (including openness, participation in decision making, dialogue with the hospital management). ${ }^{19}$

Hospital doctors had a fairly high proportion of risky levels of work stress across all three of our measuring points, and they had significantly higher proportions of risky work-stress levels than private practice specialists. We found no significant changes either on the item level or on the proportion of risky level of work stress among hospital doctors, doctors in academia and private practice specialists (figure 2, table 2). A possible reason for the low proportion of risky levels of work stress among private practice specialists could be their higher autonomy in managing their workload. ${ }^{1125}$

Changes in expectations among younger GPs and doctors in general may also explain some of the increase in perceived work stress. Doctors who work part time when their children are small report less work stress and especially less work-home stress. ${ }^{37}$ Being a hospital employee probably facilitates part-time work rather than being self-employed, as most GPs in Norway are.

\section{Strengths and limitations}

The main strengths of the study are its repeated measurements and the fact that the respondents are near representative of practising doctors in Norway. This gives us a good basis for generalisation. A concern is that the distribution of some job positions varied slightly between our sample and the Statistics on all Members of the Norwegian Association in 2018-2019 (table 1). However, it did not bias the results because we analysed the data across job positions. It must be acknowledged that not the same cohort was followed up over time, although many of the respondents replied at all three points in time. The sample represents an unbalanced cohort in that respondents who leave the panel due to retirement, death or voluntary withdrawal were replaced by younger doctors, while the sample's representative nature is maintained at all times. The unbalanced cohort was supplemented with young doctors in 2016. Thus, the demographic characteristics between the 3 years groups were slightly different: Age in years and the proportion of females were similar in 2016 and 2019. The sample in 2010 had a lower proportion of females and higher age in years than the samples in 2016 and 2019. However, statistical analyses on experienced work stress measured as ERI were controlled for age and gender at the three time points. Furthermore, the response rates were good, ranging from $67 \%$ to $75 \%$, which are higher than for other surveys of the medical profession, ${ }^{12}$ but do not rule out the possibility of nonresponse bias. It is possible that the doctors with a particularly heavy workload and more stress were more reluctant to respond to the questionnaires giving an underestimation of work-stress level. On the other hand, doctors with high stress might to a larger degree want to express their opinion. Another limitation is that we do not know whether there is a tendency in our sample towards overor underestimation of the various components of working conditions in the ERI questionnaire, or whether there are job-position differences in the self-reporting. However, our follow-up of the unbalanced cohort also showed changes in the partly overlapping samples of doctors over time, which gives us valid data on changes in work stress. Another limitation is that we only have self-reported data, although this is a plausible methodology. The ERI questionnaire was not specifically designed for doctors, but has been validated ${ }^{25}$ and used extensively in doctor populations, both in Norway and elsewhere. ${ }^{5} 122538$ Because the perceived level of work stress varies with individual characteristics such as personality and coping style, ${ }^{39}$ it is also important to include these co-variates in future analyses. However, because the great majority of doctors have answered at all three points in time, this will not have an important impact on the changes we report in this study.

\section{Conclusion}

The study contributes to the discussion on doctors' risky levels of work stress in Western countries. The unbalanced cohort design on doctors' work stress with high response rates and near representativity of practising doctors in Norway provided a solid basis for generalisation of the results. From 2010 to 2019, the proportion of risky levels of work stress increased significantly for GPs and it stayed at a relatively high level for hospital doctors. This may be partly due to changes in expectations of younger GPs and doctors in general as well as to several healthcare reforms and regulations over the last decade.

\section{Future research and policy implications}

Variations in the proportion of risky levels of work stress across job positions and over time call for more comparative analyses in the future. Reducing risky levels of workrelated stress among Norwegian doctors is important and has been found to improve both doctors' health and quality of patient care, ${ }^{28} 40-42$ and work stress is an important factor for career decisions such as staying in or leaving job positions. ${ }^{27} 43$ In a recent study from 
Sweden, almost every third graduating doctor reported that they are 'likely' or 'very likely' to leave the profession completely during a 5-year period due to high workload, stress and poor working environment. ${ }^{44}$ According to another recent study among health professionals in Switzerland, reduction of work stress in the forms of work-life and ERI (particularly rewards components) seemed to reduce both burnout and intention to leave. ${ }^{27}$ We found in our sample that specific attention should be paid to the GPs with the highest levels of work-related stress in 2016 and 2019, and also hospital doctors with stable high levels of risky work stress at all three time points. Low recruitment to primary care is a concurrent issue in Norway. ${ }^{45} 46$ To improve the working conditions of doctors and reduce work stress may cause more doctors to remain in, or choose, general practice. It may be achieved by reducing the 'effort' aspects of the work (including time pressure, many interruptions, high responsibility, increasing demand) and increasing the 'reward' aspects of the work (including promotion prospects, undesirable changes, job security, respect and prestige, adequate income).

Acknowledgements The authors wish to thank all doctors who have supported this study by participating in the survey.

Contributors JR, KIR and OGA designed the study. JR undertook the literature review, did the statistical analysis and wrote the first draft. KIR, FB and OGA made critical revisions. All authors had full access to all of the data (including statistical reports and tables) and are jointly responsible for the integrity of the data and the accuracy of the data analysis.

Funding The authors have not declared a specific grant for this research from any funding agency in the public, commercial or not-for-profit sectors.

Competing interests None declared.

Patient consent for publication Not required.

Ethics approval According to the Regional Committee for Medical Research Ethics, the study based on 'Norwegian Physician Survey - A biennial prospective questionnaire survey of a representative sample of Norwegian physicians' is exempt from review in Norway, cf. $\S \S 4$ of The Act. The project can be implemented without the approval by the Regional Committee for Medical Research Ethics (IRB 0000 1870). All invitees received a letter with a description of the 'Norwegian Physician Survey' aim. It was also explained that participation is voluntary and the data would be handled confidentially.

Provenance and peer review Not commissioned; externally peer reviewed.

Data availability statement Data are available on reasonable request. The authors may be able to provide aggregated data on which the analysis is based, on request. No additional data available.

Open access This is an open access article distributed in accordance with the Creative Commons Attribution Non Commercial (CC BY-NC 4.0) license, which permits others to distribute, remix, adapt, build upon this work non-commercially, and license their derivative works on different terms, provided the original work is properly cited, appropriate credit is given, any changes made indicated, and the use is non-commercial. See: http://creativecommons.org/licenses/by-nc/4.0/.

ORCID iD

Judith Rosta http://orcid.org/0000-0003-3735-3355

\section{REFERENCES}

1 Montgomery A, Panagopoulou E, Esmail A, et al. Burnout in healthcare: the case for organisational change. BMJ 2019;366:14774.

2 Panagioti M, Geraghty K, Johnson J, et al. Association between physician burnout and patient safety, professionalism, and patient satisfaction: a systematic review and meta-analysis. JAMA Intern Med 2018;178:1317-30.
3 Maslach C, Schaufeli WB, Leiter MP. Job burnout. Annu Rev Psychol 2001;52:397-422.

4 Siegrist J. Adverse health effects of high-effort/low-reward conditions. J Occup Health Psychol 1996;1:27-41.

5 Knesebeck O, Klein J, Grosse Frie J, et al. Psychosocial stress among hospital doctors in surgical fields. Deutsches Arzteblatt 2010;107:248-53.

6 Schreuder JAH, Roelen CAM, Koopmans PC, et al. Effort-reward imbalance is associated with the frequency of sickness absence among female Hospital nurses: a cross-sectional study. Int J Nurs Stud 2010;47:569-76.

7 Peter R, Siegrist J. Chronic work stress, sickness absence, and hypertension in middle managers: general or specific sociological explanations? Soc Sci Med 1997;45:1111-20.

8 Siegrist J. Effort-reward imbalance at work and cardiovascular diseases. Int J Occup Med Environ Health 2010;23:279-85.

9 Dragano N, Siegrist J, Nyberg ST, et al. Effort-reward imbalance at work and incident coronary heart disease: a multicohort study of 90,164 individuals. Epidemiology 2017;28:619-26.

10 Siegrist J, Li J. Associations of extrinsic and intrinsic components of work stress with health: a systematic review of evidence on the effort-reward imbalance model. Int J Environ Res Public Health 2016;13:432-32.

11 Rosta J, Aasland OG, Nylenna M. Changes in job satisfaction among doctors in Norway from 2010 to 2017: a study based on repeated surveys. BMJ Open 2019;9:e027891.

12 Voltmer E, Rosta J, Siegrist J, et al. Job stress and job satisfaction of physicians in private practice: comparison of German and Norwegian physicians. Int Arch Occup Environ Health 2012;85:819-28.

13 Rosta J, Aasland OG. Doctors' working hours and time spent on patient care in the period 1994 - 2014. Tidsskr Nor Legeforen 2016;136:1355-9.

14 Rebnord IK, Eikeland OJ, Hunskar S, et al. Fastlegers tidsbruk (GPS working time). Bergen: National Centre for Emergency Primary Care, 2018.

15 Morken T, Rebnord IK, Maartmann-Moe K, et al. Workload in Norwegian general practice 2018 - an observational study. BMC Health Serv Res 2019;19:434-34.

16 Pedersen Fischer A, Busk Noroxe K, Bro F, et al. Alment praktiserende lægers psykiske arbejdsmiljo OG jobtilfredshed 2016 (General practitioners' psychological work environment and job satisfaction 2016). Aarhus: Research Unit for General Practice, 2016.

17 Scott A. General practice trends. Melbourne: Melbourne Institute health sector, 2017. Available: https://mabel.org.au/_data/assets/ pdf_file/0005/2334551/ANZ-MI-Health-Sector-Report.pdf

18 Gibson J, Sutton M, Spooner S, et al. Ninth national GP worklife survey. Manchester: University of Manchester, 2017. Available: http://blogs.Ishtm.ac.uk/prucomm/files/2018/05/Ninth-National-GPWorklife-Survey.pdf

19 Ramboll. Sporreskjemaundersokelse - sykehuslegers arbeidsforhold 2018 (Survey on hospital doctors working conditions 2018). Available: https://www.dagensmedisin.no/contentassets/b79cfab9 9ba6437bb3ccf9efa9ad75aa/sporreundersokelse-om-sykehuslegersarbeidsforhold-2018.pdf [Accessed 10 Jan 2020].

20 Baathe F, Rosta J, Bringedal B, et al. How do doctors experience the interactions among professional fulfilment, organisational factors and quality of patient care? A qualitative study in a Norwegian hospital. BMJ Open 2019;9:e026971.

21 McKevitt C, Morgan M, Dundas R, et al. Sickness absence and 'working through' illness: a comparison of two professional groups. J Public Health Med 1997;19:295-300.

22 Heponiemi T, Kouvonen A, Sinervo T, et al. Is the public healthcare sector a more strenuous working environment than the private sector for a physician? Scand J Public Health 2013;41:11-17.

23 Virtanen P, Oksanen T, Kivimäki M, et al. Work stress and health in primary health care physicians and hospital physicians. Occup Environ Med 2008;65:364-6.

24 Siegrist J, Starke D, Chandola T, et al. The measurement of effortreward imbalance at work: European comparisons. Soc Sci Med 2004;58:1483-99.

25 Siegrist J, Shackelton R, Link C, et al. Work stress of primary care physicians in the US, UK and German health care systems. Soc Sci Med 2010;71:298-304.

26 Statistics on all Members of the Norwegian Medical Association. Practicing doctors in Norway $<70$ years - 2018. Available: https:// betalegeforeningenno/om-oss/legestatistikk/yrkesaktive-leger-inorge/ [Accessed 05 Jan 2020].

27 Hämmig O. Explaining burnout and the intention to leave the profession among health professionals - a cross-sectional study in a hospital setting in Switzerland. BMC Health Serv Res 2018;18:785-85. 
28 Loerbroks A, Weigl M, Li J, et al. Effort-reward imbalance and perceived quality of patient care: a cross-sectional study among physicians in Germany. BMC Public Health 2016;16:342.

29 The Department of Occupational Health Surveillance (NOA). Innsatsbelonning-ubalanse (Effort-Reward Imbalance). Available: https:// noa.stami.no/tema/psykososialtorganisatorisk/innsats-belonning/ [Accessed 01 Feb 2019].

30 McKinlay JB, Marceau L. New wine in an old bottle: does alienation provide an explanation of the origins of physician discontent? Int $J$ Health Serv 2011;41:301-35.

31 Forde R, Aasland OG. Moralsk stress og faglig ytringsfrihet blant leger (Moral distress and professional freedom of speech among doctors). Tidsskr Nor Legeforen 2013;12-13:1310-3.

32 Johnsen T, Berge V, Hoivik F, et al. Tronderopprorets fastlegeundersokelse og helsemedarbeiderundersokelse 2018 (Survey on GPs and health workers, 2018).http://www.flo20.no/wpcontent/uploads/2018/06/TOundersøkelse-2.pdf [Accessed 05 Jan 2020].

33 Lehn H. Utvikling i bruk av fastlege og legevakt: Analysenotat $i$ Samdata kommune (Development in the use of GP-service and emergency medical service). Oslo: The Norwegian Directorate of Health, 2018

34 Malterud K, Aamland A, Fosse A. How can task shifting put patient safety at risk? a qualitative study of experiences among general practitioners in Norway. Scand J Prim Health Care 2020;38:24-32.

35 Regjeringen.no. Evaluering av fastlegeordningen 2019 (Evaluation of the regular general practitioners scheme 2019).https://www. regjeringen.no/no/aktuelt/fastlegeordningen-er-evaluert/id2667485/ [Accessed 05 Jan 2020].

36 Tomioka K, Morita N, Saeki K, et al. Working hours, occupational stress and depression among physicians. Occup Med $2011 ; 61: 163-70$
37 Hertzberg TK, Tyssen R, Skirbekk H, et al. Work-home balance in two cohorts of Norwegian doctors. Tidsskr Nor Legeforen 2019;139:915-20.

38 Rosta J, Tellnes G, Aasland OG. Differences in sickness absence between self-employed and employed doctors: a cross-sectional study on national sample of Norwegian doctors in 2010. Health Serv Res 2014:14:1-8.

39 Parkes KR. Personality and coping as moderators of work stress processes: models, methods and measures. Work Stress 1994;8:110-29.

40 Firth-Cozens J, Greenhalgh J. Doctors' perceptions of the links between stress and lowered clinical care. Soc Sci Med $1997: 44: 1017-22$

41 Angerer P, Weigl M. Physicians' psychosocial work conditions and quality of care: a literature review. PP 2015;5:1-20

42 Weigl M, Hornung S, Angerer P, et al. The effects of improving hospital physicians working conditions on patient care: a prospective, controlled intervention study. BMC Health Serv Res 2013;13:401.

43 Scanlan JN, Still M. Relationships between burnout, turnover intention, job satisfaction, job demands and job resources for mental health personnel in an Australian mental health service. BMC Health Serv Res 2019;19:62.

44 Petterson J, Börjesson J. I väntan på AT: En samhällsekonomisk studie 2019 (Waiting for intership: a socio-economic study 2019). Available: https://slfse/sylf/app/uploads/2019/07/i-vantan-pa-atpdf [Accessed 05 Jan 2020]

45 Kjosavik SR. Ongoing recruitment crisis in Norwegian general practice. Scand J Prim Health Care 2018;36:107-8.

46 Korsvold L, Tonnessen C, Sirnes E, et al. Leger i kommune- og spesialisthelsetjenesten (Doctors in municipal and specialist health service). Oslo: The Norwegian Directorate for Health, 2017. 